\title{
Clinical and radiographic outcomes of rhomboid plate in management of subcondylar fractures: prospective randomized controlled trial
}

Original

Article

\author{
Mohamed H. Ashor, Ahmed M. Salah, Mustafa I. Shindy, Heba A.E. Selim, Salah \\ A.E. Metwaly and Galal G.E. Behairy \\ ${ }^{a}$ Faculty of Dentistry, Ain Shams University and ${ }^{b}$ Ahmed Maher Teaching Hospital, Cairo, \\ Egypt
}

\begin{abstract}
Purpose: The aim of this study was to compare the clinical and radiological outcomes of treatment of mandibular subcondylar fractures using three-dimensional rhombus plates versus two miniplates techniques.

Patients and Methods: A total of 20 patients having subcondylar fractures indicated for open reduction and plate fixation were recruited from Ahmed Maher Teaching Hospital and Faculty of Dentistry, Ain Shams University, and randomly divided into two equal groups. Study group was treated using three-dimensional rhombus plates, and the control group was treated using two miniplates (2.0): one parallel to posterior border of the mandible and the other parallel to sigmoid notch. The clinical and radiological outcomes of the treatment such as bone fixation stability, occlusion, mandibular movements, time of fixation, and cost of hardware were assessed and statistically analyzed.

Results: There was no statistically significant difference between the two groups in all comparisons except time of fixation and cost of hardware, as three-dimensional rhombus plates were more costly and time saving.

Conclusion: Three-dimensional rhombus plate has clinical and radiographic outcomes comparable to two miniplates, offering less operative time, with strong recommendation for high subcondylar fracture.
\end{abstract}

Received: $20^{\text {th }}$ November, 2017, Accepted: $20^{\text {th }}$ December, 2017.

Key Words: mandibular condyle, open reduction and rigid internal fixation of mandibular condylar fractures, subcondylar fractures, three-dimensional rhombus plate.

Corresponding Author: Mohamed H. Ashor, Dr Hamdy Ashor House, Schwbrament, Almariottia, Al Haram, Giza, Egypt Tel.: + 20233635 164, E-mail: mrashooor@gmail.com

ISSN: 2090-097X, January, Vol. 9, No. 1.

\section{INTRODUCTION}

Condylar fracture has high incidence among maxillofacial casualties. Management of condylar fracture aims for restora tion of mandibular continuity, TMJ function as well as preatruma occlusion with minimal cost and morbidity [1-3].

Many research studies have been done exhausting comparison between closed and open treatment. Our work evaluates a new type of hardware used for open reduction and rigid fixation of subcondylar fracture, assuming easier application and less cost compared with standard two miniplates system [4-8].

\section{AIM}

The aim of the study was to clinically and radiographically assess outcomes of treating subcondylar fractures using three-dimensional rhombus plate.

\section{PATIENTS AND METHODS}

A total of 20 cases of subcondylar fractures indicated for open reduction and rigid internal fixation were incorporated in the study. Cases were recruited from outpatient clinics in Faculty of Dentistry, Ain Shams University, and Ahmed Maher Teaching Hospital. Cases were randomly divided into two equal groups: study group A was treated using 
rhombus plates, and control group B was treated using two miniplates' osteosynthesis.

\section{PREOPERATIVE RECORDS AND PREPARATION}

Preoperative examination included personal history, history of trauma, clinical examination of TMJ as well

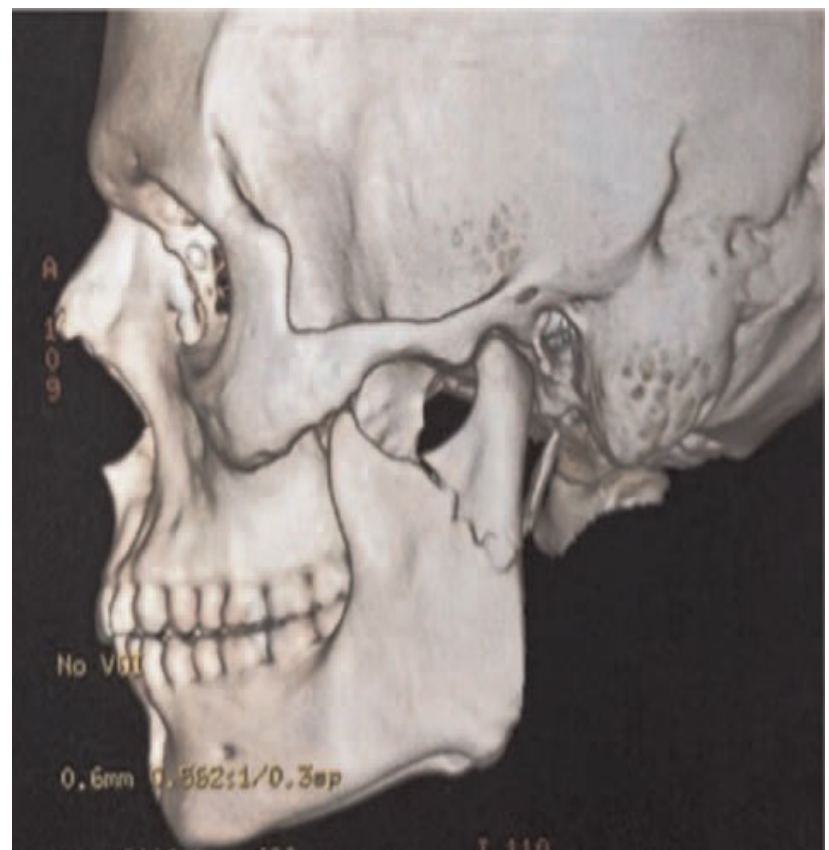

Fig. 1: Preoperative computed tomogram of subcondylar fracture. as associated injuries and occlusion. Radiographic examination was done with multislice computed tomograms and three-dimensional reconstructed images (Fig. 1).

Upper and lower arch bars were fixed to available teeth to regain pretrauma occlusion.

\section{OPERATIVE PROCEDURE}

Patients were operated under general anesthesia with endotracheal intubation, and fracture sites were exposed through modified retromandibular approach with careful dissection posterior and below parotid capsule avoiding facial nerve injury. Fractured proximal segment was reduced and fixed with rhombus plate or two miniplates, and then occlusions were checked and the wound closed in layers (Fig. 2).

\section{POSTOPERATIVE CARE}

Heavy elastics were used for 3 days postoperatively followed by light elastics for another 4 days to limit interfragmentary movements and minimize postoperative pain. Analgesics, anti-inflammatory drugs, antibiotics, and antiseptic mouthwash were used for 5 days postoperatively. Skin sutures were removed 1 week postoperatively and joint function was checked. Arch bars were removed 2 weeks postoperatively. Postoperative records (records obtained immediately and 2 months postoperatively):
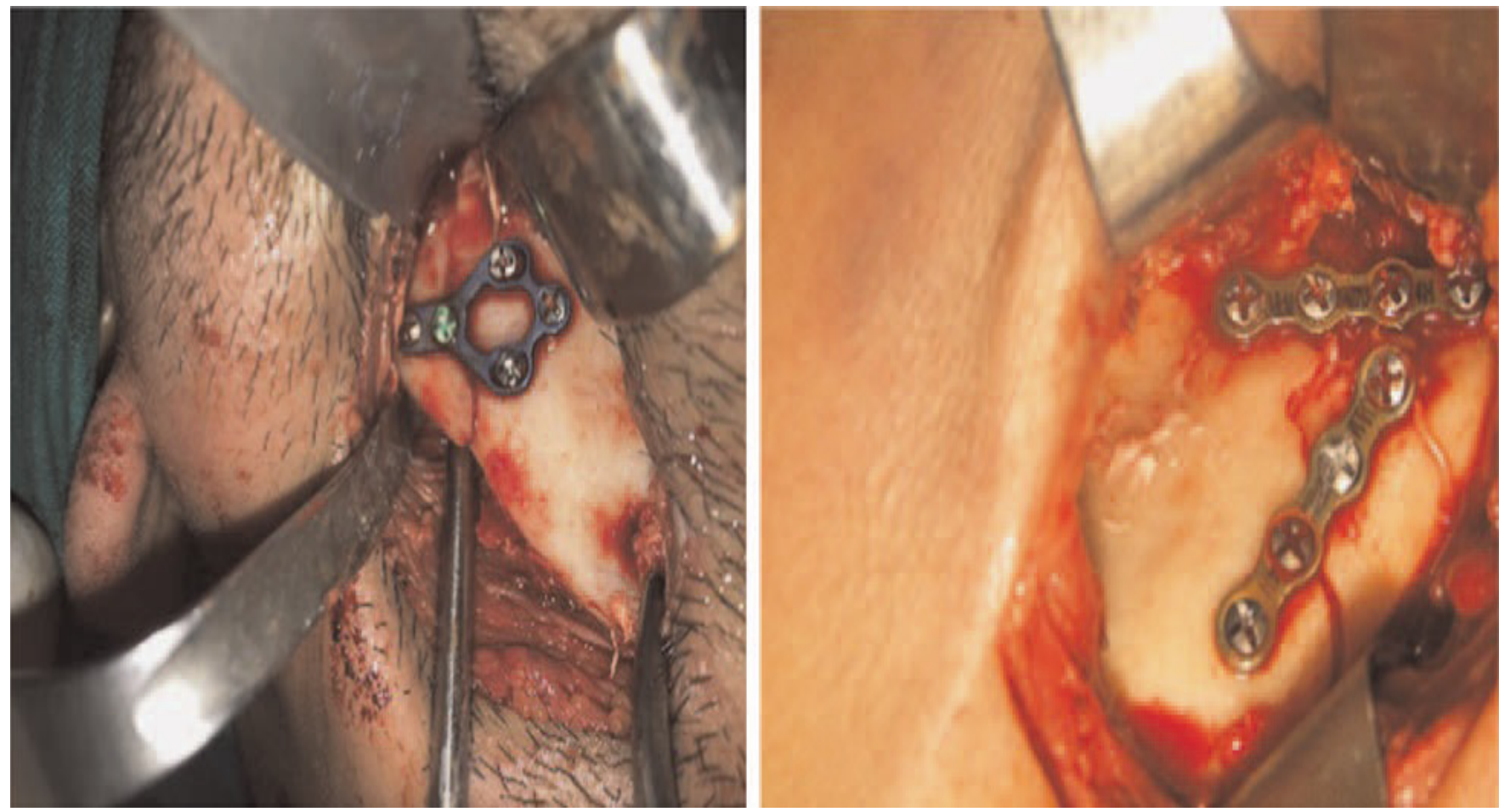

Fig. 2: Intraoperative photograph showing plate fixation of subcondylar fracture using three-dimensional rhombus plate or two four-holes miniplates 

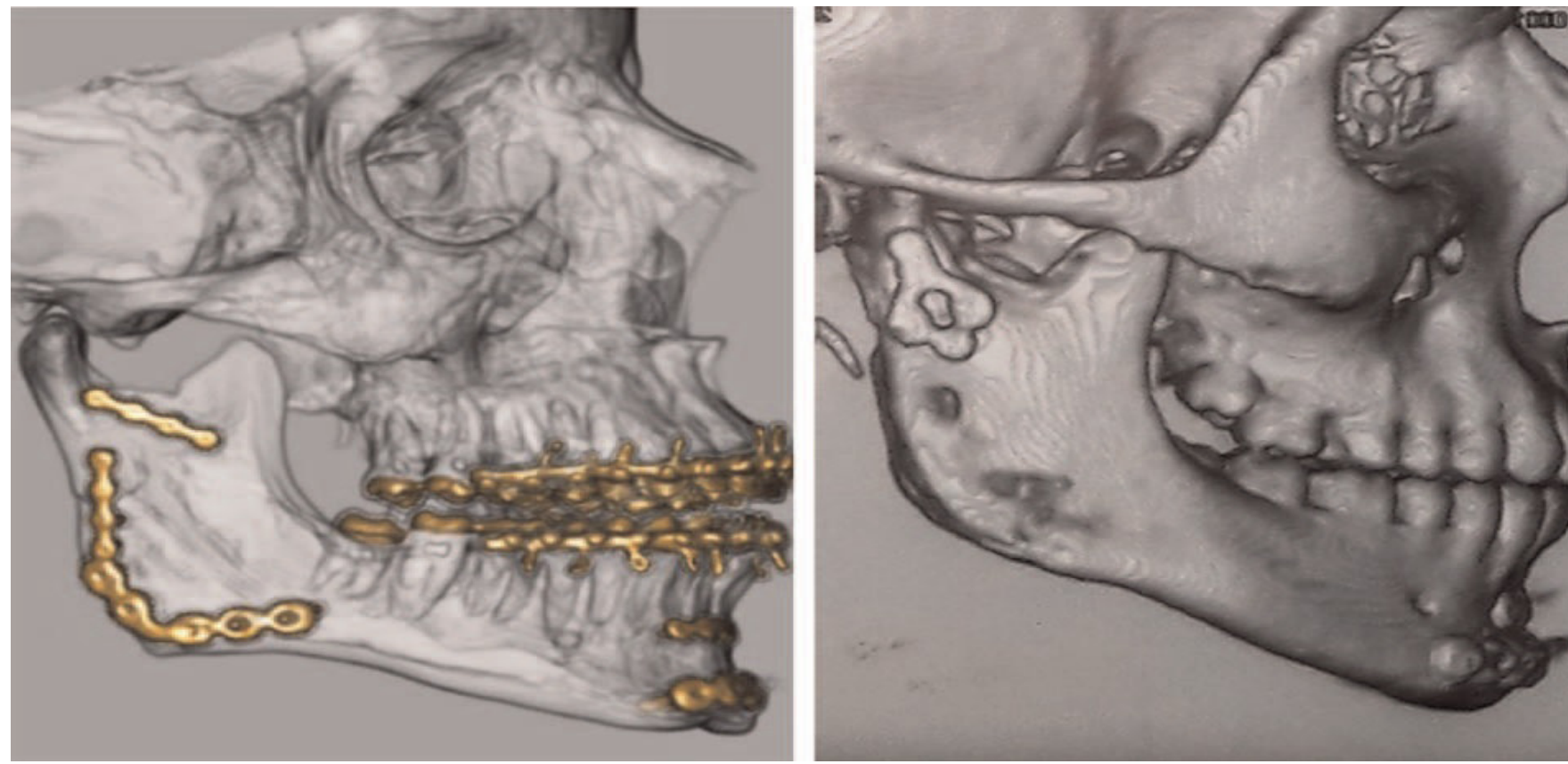

Fig. 3: Postoperative computed tomogram showing subcondylar fractures using two miniplates and three-dimensional rhombus plate.
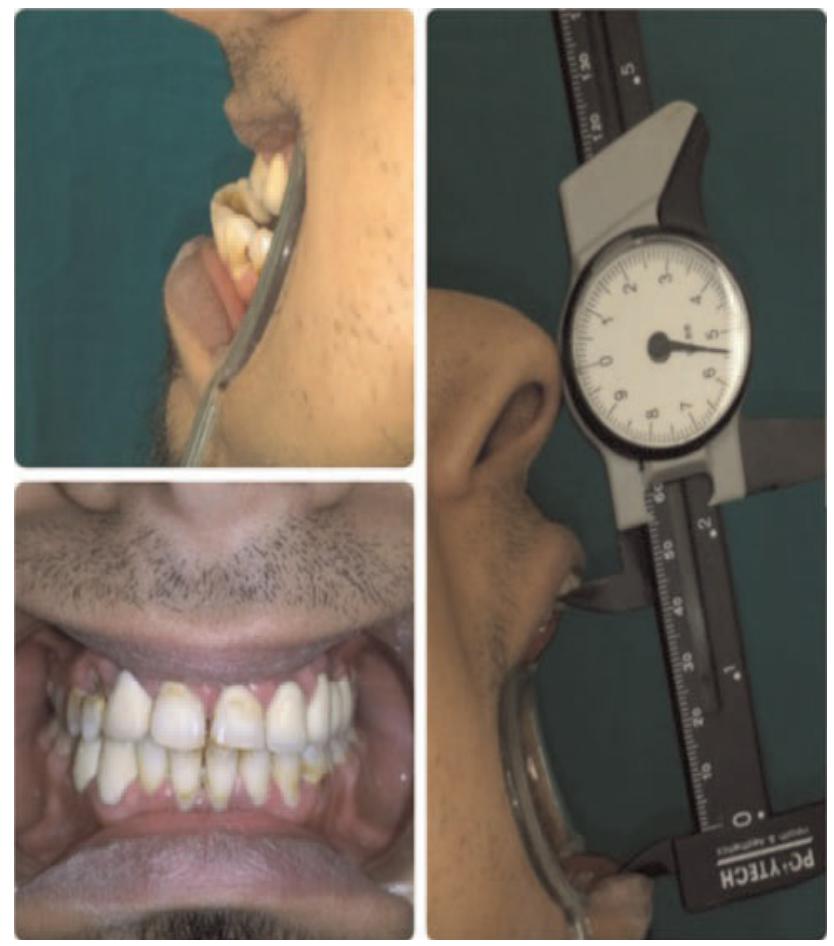

Fig. 4: Postoperative photograph showing postoperative records of occlusion, maximum mouth opening, and protrusive movements.

1. Computed tomograms with three-dimensional reconstructed images were obtained to check adequate reduction of the fracture segment and condylar position (Fig. 3).

2. Maximum nonassisted mouth opening, mandibular movements, and occlusion were recorded. Time of fixation, cost of hardware, and operative and postoperative complications were also assessed (Fig. 4).

\section{RESULTS}

All the collected data were tabulated and statistically analyzed with intergroup and intragroup comparisons. All patients tolerated the surgical procedure with clinically and radiographically acceptable results regarding stability of bone segments and occlusion. There was no statistically significant difference between the two groups.

\section{STABILITY OF BONE REDUCTION, POSTOPERA- TIVE OCCLUSION, AND DEVIATION OF MAN- DIBULAR MIDLINE}

There was no statistically significant difference in bone stability, postoperative occlusion, and deviation of mandibular midline across study time regarding both intragroup and intergroup comparisons.

\section{LATERAL AND PROTRUSIVE MOVEMENTS AND MAXIMUM MOUTH OPENING (INTERINCISAL DISTANCE; MILLIMETERS)}

There was a statistically significant difference regarding lateral and protrusive movements and maximum mouth opening (interincisal distance; millimeters) between immediately postoperatively and 2 months postoperatively in intragroup comparisons in both groups. However, intergroup comparisons showed no statistically significant difference in protrusive and lateral movements both immediately postoperatively and 2 months postoperatively. 


\section{COST OF PLATES AND SCREWS}

The study group showed statistically significant cheaper hardware cost (in Egyptian pounds) than control group, with mean costs of $650.01 \pm 0.03$ and $900.02 \pm 0.06$, respectively.

\section{TIME OF REDUCTION AND FIXATION}

The study group showed statistically significant shorter operative time than control group, with mean time of $34.70 \pm 4.40$ and $50.00 \pm 6.24$, respectively.

\section{ASSOCIATED COMPLICATIONS}

1. Marginal mandibular nerve affection was found in three cases (one case of the study group and two control cases). One case recovered after 2 months, and the other two cases recovered after 6 months.

2. Lip paresthesia was recorded in one case preoperatively associated with body fracture, and the patient was followed up for 6 months, where nerve regains its sensory function again.

3. Hypertrophic scar was seen as late manifestation of wound healing in two cases, where plastic consultation was done, and silicone creams or patches were initiated.

\section{DISCUSSION}

Proper selection of the hardware type is very crucial for successful treatment of condylar fracture. Many factors should be considered during selection of hardware, including age of the patient, associated fractures, available resources and equipment, skills of the operator, and lastly the level of fracture line. Both clinical practice and literature consider double miniplates as gold standard for fixation of subcondylar fracture. However, the use of two miniplates has some drawbacks such as higher cost of hardware, longer operation time, and some technical difficulty in fixation especially in high subcondylar fractures, severely displaced fractures, and small proximal segment fractures [9].

The use of one miniplate fixation technique is hazardous and usually accompanied by many problems such as screws loosening, plate bending, plate fracture, and inadequate stability of fixation [10].

Mezitis et al. [11] in a retrospective study of 45 patients concluded that reduction with single plate either compression or noncompression produces inadequate stability with disturbed postoperative bone reduction, whereas double miniplates produces good postoperative stability and reduction, but it usually demands greater tissue dissection and detachment, which may lead to limitation of mouth opening $[11,12]$

In a continuous search of better hardware designs, there is a revolution of what was called threedimensional plate; rhombus plate used in the present study is one of those. The two arms of the rhombus part mechanically act as compression and tension plates. Tensile strains occur mainly at the anterior and lateral borders of the condyle and compressive strains, at the posterior and medial borders owing to the permanent mediolateral bending of the condyle during function. So the design could be functioning as tension and compression plates at the same time with only two vertical screws in proximal segments which could be easily accommodated in small segments and higher level fractures [13].

Comparable results could be achieved with an A-shaped plates, another type of three-dimensional plate, as concluded by Kozakiewicz et al. [13]. Clinical application of A-shaped plate was as versatile as makes possible to simultaneous fixation of high condylar neck and coronoid process fracture. Moreover, it could be used for all levels of condylar neck fracture [13-17]

Anchlia et al. [18] had performed a comparative clinical study to evaluate lambda plates versus delta plates using modified mini-retromandibular subparotid approach, and the results found no difference between two plating designs, but the approach was more conservative, tissue sparing, and with less complications.

Although finite element studies proved superiority of two miniplates over all other hardware designs, three-dimensional plates show clinically comparable outcomes, with easier application, less cost, and shorter fixation time [19].

Based on the results of the current research, the use of rhomboid plate is recommended especially in higher level fractures over two miniplates, as it is easier in fixation and could easily be accommodated with small proximal segments. Moreover, it offers reduction of the total treatment fees, as it has cheaper hardware and shorter operative time.

In cases with large proximal condylar segment or those with more one line of fracture, it is recommended to use two miniplates as it gives more rigid stabilization in three-dimensional directions with better resistance to torsional forces. 


\section{CONFLICT OF INTEREST}

None declared.

\section{REFERENCES}

1. Snyder SK, Cunningham LL. The biology of open versus closed treatment of condylar fractures. Atlas Oral Maxillofac Surg Clin 2017; 25:35-46.

2. Choi K-Y, Yang J-D, Chung H-Y, Cho B-C. Current concepts in the mandibular condyle fracture management part II: open reduction versus closed reduction. Arch Plast Surg 2012; 39:301-308.

3. Haug RH, Assael LA. Outcomes of open versus closed treatment of mandibular subcondylar fractures. J Oral Maxillofac Surg 2001; 59: 3706-5.

4. Dijkstra PU, Stegenga B, de Bont LGM, Bos RRM. Function impairment and pain after closed treatment of fractures of the mandibular condyle. J Trauma 2005; 59:424-430.

5. Danda AK, Muthusekhar MR, Narayanan V, Baig MF, Siddareddi A. Open versus closed treatment of unilateral subcondylar and condylar neck fractures: a prospective, randomized clinical study. J Oral Maxillofac Surg 2010; 68:1238-1241.

6. Sforza C, Ugolini A, Sozzi D, Galante D, Mapelli A, Bozzetti A. Threedimensional mandibular motion after closed and open reduction of unilateral mandibular condylar process fractures. J Craniomaxillofacial Surg 2011; 39:249-255.

7. Al-Moraissi EA, Ellis E. Surgical treatment of adult mandibular condylar fractures provides better outcomes than closed treatment: a systematic review and meta-analysis. J Oral Maxillofac Surg $2015 ; 73: 482-493$.

8. Kang DH. Surgical management of a mandible subcondylar fracture. Arch Plast Surg 2012; 39:284-290.

9. Lauer G, Haim D, Proff P, Richter G, Pradel W, Fanghänel $\mathrm{J}$, et al. Plate osteosynthesis of the mandibular condyle. Ann Anat 2007; 189: 412417.

10. Lee J-W, Lee Y-C, Kuo Y-L. Reappraisal of the surgical strategy in treatment of mandibular condylar fractures. Plast Reconstr Surg 2010; 125:609-619.

11. Mezitis M, Zachariades D. Plate osteosynthesis of condylar fractures: a retrospective study of 45 patients. Quintessence Int 2003; 34:45-49.

12. Choi BH, Yi CK, Yoo JH. Clinical evaluation of 3 types of plate osteosynthesis for fixation of condylar neck fractures. J Oral Maxillofac Surg 2001; 59:734-737.

13. Kozakiewicz M, Swiniarski J. 'A' shape plate for open rigid internal fixation of mandible condyle neck fracture. J Craniomaxillofacial Surg 2014; 42:730-737.

14. 14 Seemann $R$, Schicho K, Reichwein A, Eisenmenger G, Ewers R, Wagner A. Clinical evaluation of mechanically optimized plates for the treatment of condylar process fractures. Oral Surg Oral Med Oral Pathol Oral Radiol Endodontol 2007; 104:1-4.

15. Singh G, Mohammad S, Das S, Passi D, Vishwakarma K. Trapezoidal condylar plate: report of 15 cases in the management of mandibular subcondylar fracture. J Adv Med Dent Sci 2013; $1: 13-18$

16. Anirudhan A, Khalam SA, Zachariah RK. Evaluation of clinical use of indigenously developed delta plate in management of subcondylar fracture. Clin Pract 2013; 3:e28.

17. Cortelazzi R, Altacera M, De Benedittis M, Turco M, Antonicelli V. Development and clinical evaluation of MatrixMANDIBLE Subcondylar Plates System (Synthes). Craniomaxillofac Trauma Reconstr 2015; 8:94-99.

18. Anchlia S, Parmar R, Nagwadia V, Dhuvad J, Shah J, Domadia H. Twodimensional lambda versus three-dimensional delta plates in subcondylar fracture using modified mini retromandibular subparotid approach. Int J Oral Maxillofac Surg 2017; 46:256

19. Costa FWG, Bezerra MF, Ribeiro TR, Pouchain EC, Sabóia VDPA, Soares ECS. Biomechanical analysis of titanium plate systems in mandibular condyle fractures: a systematized literature review. Acta Cir Bras 2012; 27: 424-429. 